\title{
LA INVENCIÓN PRÁCTICA DEL CONSENSO. JUSTICIA Y ACUERDOS ANTE NOTARIO EN CHILE (SIGLOS XVII Y XVIII)
}

\author{
PRACTICAL INVENTION OF CONSENSUS. \\ JUSTICE AND AGREEMENTS WITH A NOTARY IN CHILE \\ (XVII-XVIII CENTURIES)
}

\begin{abstract}
Aude Argouse*
El objetivo de este texto es mostrar que el estilo notarial, sus fórmulas y prácticas, participaron, en Santiago de Chile de fines del siglo XVII y durante el siglo XVIII, en la construcción política del consenso. El oficio del escribano es un lugar de primera importancia, donde convergen la resolución de conflictos y la invención práctica del consenso. Para eso, interrogamos los motivos para llegar a un acuerdo ante escribano y mostramos que más allá de la reducción de gastos se hace al precio de una abdicación voluntaria de la soberanía individual, en nombre de un principio sagrado y antiguo que es el de la concordia. El significado político de esta práctica en una sociedad colonial del Antiguo Régimen está cuestionado sobre la base de los contratos ante escribanos.

Palabras claves: Acuerdos, conflictos, escribano, Chile, siglos XVII y XVIII.

This text aims to show that the notarial style, its formulas and practices, participated in Santiago de Chile at the end of the 17th century and during the 18th century, in the political construction of consensus. The notary's office is a place of primary importance where the resolution of conflicts and the practical invention of consensus converge. Hence, we question the motivations to set a notarial agreement and highlight that beyond the expense reduction, this is done at the price of a voluntary abdication of individual sovereignty in the name of a sacred and ancient principle that is that of concord. The political significance of this practice in a colonial society of the Old Regime is questioned on the basis of notarial agreements.
\end{abstract}

Key words: Agreements, conflicts, notary, Chile, 17th-18th Century.

\section{Introducción}

This Kindness will I show.

Go with me to a notary, seal me there Your single bond, and, in a merry sport, If you repay me not on such a day, In such a place, such sum or sums as are Express'd in the condition, let the forfeit $B e$ nominated for an equal pound Of your fair flesh, to be cut off and taken In what part of your body pleaseth me.

Shylock, The Merchant of Venice

En Chile, los comienzos del período colonial corresponden tradicionalmente a una fase de conflictos, seguida por un período de "estabilización" -pese a la guerra defensiva contra los Indios del Sur-con acentos profilácticos: "nuestro enfermo y lastimado Chile", dice Francisco Núñez de Pineda y
Bascuñán en su famosa obra Cautiverio feliz (Núñez de Pineda y Bascuñán 2001 [1673]: 187). La Batalla de Curalaba en 1598 termina un primer período, pero la "estabilidad" anunciada en la historiografía nunca parece haber llegado: el largo siglo XVII está marcado por guerras, levantamientos, epidemias, terremotos y escándalos. Sin embargo, la observación de una discreta pero creciente presencia de instrumentos notariales tales como convenios, transacciones y acuerdos, en Santiago de Chile en los siglos XVII y XVIII, permite plantear que los registros de escribanos cumplen una función política que consiste en establecer una sociedad civil viable.

El Reino de Chile se caracteriza por una masa demográfica baja en sus centros urbanos y su gobierno está en manos de un núcleo de personas cuya acción política consiste, sobre todo, en controlar los tribunales con el fin de presentar un margen de maniobra mayor en la conducción de sus negocios y méritos. Así, la reputación que este territorio parece haber adquirido, no se contradice con los relatos

\footnotetext{
* Centro de Estudios Históricos, Universidad Bernardo O’Higgins. Facultad de Derecho, Universidad de Chile. Santiago, Chile. Correo electrónico: oddargo@gmail.com
} 
de los contemporáneos en sus súplicas al rey y a su consejo ni por la historiografía tradicional chilena. Por ejemplo, lo que llamó la atención de los historiadores chilenos del siglo XIX fueron sobre todo las acciones de conquista y gloria llevadas a cabo en los indomables territorios del sur.

Este marco histórico constituido por antagonismos y tensiones irreductibles contrasta $a$ priori con la estabilidad de la institución notarial. En efecto, una mirada más atenta a los archivos de los escribanos de la ciudad de Santiago para los siglos XVII y XVIII revela que las principales causas de inestabilidad política y económica que la historiografía ha identificado, en particular la guerra contra los indios y los terremotos, dan paso a muchos pequeños factores de estabilidad en la vida cotidiana: convenios, poderes, contratos, peticiones. Al lado de las recriminaciones dirigidas al Consejo de Indias y de los informes oficiales que ofrecen un cuadro pesimista del estado del reino aún amenazado por la ruina, los archivos notariales de Santiago muestran un universo social dinámico tejido de acuerdos y promesas entre individuos de diferentes grupos sociales.

Existen cinco escribanías del número a lo largo del siglo XVII, cifra que aumenta a nueve escribanías a finales del siglo XVIII y a la que hace falta agregar los escribanos reales (diecisiete para los siglos XVII y XVIII [Thayer Ojeda 1913: 14; Bravo Lira 1989]). La fisionomía y el aumento de los registros del fondo de escribanos de Santiago para los siglos XVII y XVIII plantea entonces varias interrogantes: ¿qué revelan los compromisos y transacciones, entre otros, respecto de las necesidades de intercambio, y de paz y justicia en una sociedad colonial? ¿Se trata del advenimiento de un derecho orientado al negocio y a los intercambios económicos? ¿Se trata de la aplicación práctica de un repertorio de acciones que "producen" consenso en un entorno precario? o ¿Es más bien la herramienta de un gobierno ansioso y atento a cualquier forma de registro?

En medio de una reconocida conflictividad política, las escrituras notariales invitan efectivamente a interrogar los elementos que potenciaron la invención del consenso y a formular la hipótesis de que pueden corresponder a una práctica destinada a dar sentido común (consensus) a la acción política, a veces tumultuosa, de las élites locales y a las tensiones que agitan al reino. Entendemos por sentido común una sensibilidad compartida cuyos rasgos pretendemos buscar en los archivos notariales. Esto permite restaurar la dimensión política de las operaciones necesarias para el establecimiento de instrumentos extrajudiciales, considerándolas como prácticas de sociabilidad, entre amistad y convenencia.

$\mathrm{Al}$ respecto, los historiadores de la América Hispana han demostrado que las cortes, tribunales y magistrados, encargados de la justicia y el gobierno de zonas a menudo muy extensas, lograron una forma de paz social utilizando hábilmente el castigo y el perdón (Agüero, 2008). Desde el punto de vista de la historia política de las ciudades y su influencia jurisdiccional en el resto del territorio, las prácticas notariales representan acciones dirigidas al advenimiento de la concordia en toda la jurisdicción.

Nuestra hipótesis se desarrolla entonces a la luz de un análisis discursivo de instrumentos notariales redactados entre 1559 y 1799 . Constituyen la base de un estudio historiográfico más amplio acerca de las prácticas de escrituración jurídica en las colonias hispanoamericanas. Constituido por un centenar de volúmenes del fondo escribanos de Santiago de los siglos XVII y XVIII, nuestro corpus nos permite examinar las formas y fórmulas de los instrumentos jurídicos así como el cuido o descuido a los registros por parte de los que los guardan (Dougnac, 1997). De hecho, el estudio tanto formal como material de los registros permite valorar cómo está considerada la preservación de la memoria pública de los acuerdos entre partes.

Así, a partir de una lectura de conjunto de los registros notariales de los siglos XVII y XVIII, observamos un sensible aumento de convenios, acuerdos y transacciones. En los tres apartados de este texto, nuestro objetivo es avanzar que 1) existe una exacerbación de la escritura notarial porque da sentido al desorden y permite liberarse de la figura del juez en un contexto colonial bordeado por la guerra y las violentas disputas ocurridas en la segunda mitad del siglo XVII; 2) esta secularización del orden jurídico aparece en los registros notariales de la Capitanía General con el paulatino aumento de convenios, acuerdos y transacciones que apuntan a resolver conflictos y más precisión en la denominación de los instrumentos por los escribanos ; 3) con la culminación de estos instrumentos ante escribanos observada para el siglo XVIII, el imperativo social del consenso entre partes se puede concebir como una forma de abdicación de sí mismo para el bien común. 


\section{Escribir y registrar para dar sentido al desorden y liberarse de la figura del juez}

Los archivos notariales santiaguinos fueron sometidos a una reordenación a principios del siglo XIX, tras una destrucción parcial de los archivos de los escribanos de la ciudad (Argouse y Soliva Sánchez, 2019). El análisis de la actividad notarial debe hacerse entonces teniendo en cuenta este maltrato archivístico y la fragmentación de los registros de la actividad notarial que resulta. A pesar de este sesgo, la perspectiva de una sociología de la acción por medio de la escritura proporciona material para un enfoque renovado de la escritura pública en una sociedad colonial.

En este marco, nuestro planteamiento es que, en un espacio urbano diez veces menos poblado que las capitales virreinales o las grandes ciudades europeas, la función práctica del escribano consiste en liberar a las partes de la figura tutelar del juez. Aunque la importancia política de los oficios de pluma no es peculiar de la América Hispana o del Reino de Chile, su utilidad práctica puede haberse visto exacerbada por la sensación de lejanía de esta Capitanía General de Chile y por la repetida percepción de la dureza de la justicia en manos de una minoría. Con varias injusticias en el horizonte, la protección de los intereses individuales así como la exaltación de los méritos en la búsqueda de la gloria, van acompañadas de una constante puesta por escrito de los acuerdos y promesas, de modo que la necesidad de un consenso escrito y auténtico resuena como una condición para la supervivencia del cuerpo social.

En efecto, la cohesión de la sociedad de Santiago de Chile, basada en dos principios de exclusión, la sangre y el linaje, está en constante tensión: la guerra con los indios del sur y las frecuentes revueltas cuyos ecos llegan a los habitantes de la capital, la presencia marítima de enemigos de España, con los que a veces hay que tratar, como por ejemplo con los franceses de Concepción a principios del siglo XVIII, o a los que hay que temer, como a los ingleses una vez que hayan cruzado el Estrecho de Magallanes. También es necesario hacer frente a las epidemias y los sismos. Tras el terremoto devastador de 1647, seguido diez años más tarde por otro terremoto muy potente, la ciudad tenía poco más de 4.000 habitantes a mediados del siglo XVII y llegaría a poco más de 12.000 en el año 1700.
Lejos de la frontera del sur de Chile, Santiago es gobernada por hombres de la Real Audiencia, en su mayoría con rangos militares, honorarios y beneficiados de un poder social similar al de una aristocracia local, cercana a los círculos comerciales y a los encomenderos, con los que acabó confundiéndose. Tenían el control de parte de los bienes y medios de producción del reino, particularmente en el suministro de vino y ropa para los ejércitos del sur. Sin embargo, la prohibición de esclavizar a los indios, decretada en 1674, frustró ciertos planes para enriquecer a las familias poderosas que se enfrentaban con comerciantes políticos de menor rango.

Después del alzamiento de 1655, que supuso la reanudación de una guerra contra los indios del sur, la década de 1660 se caracterizó por profundas desavenencias entre las diferentes facciones que llevaron al destierro del capitán general Francisco de Meneses en 1667, como resultado, entre otras, de las acciones del obispo de Santiago de Chile, Diego de Humanzoro. Durante la década siguiente, varios escándalos fueron silenciados in extremis para no despertar las sospechas de un virrey al acecho desde Lima y así asegurar la continuación de las carreras oficiales (Argouse 2016 y 2013 ).

Este contexto político ha sido ampliamente descrito por la historiografía desde el siglo XIX, por lo que no parece necesario volver a examinar aquí los términos de una lucha por el poder dentro de una oligarquía en manos de autoridades conflictivas. Pero, en este paisaje de hostilidad abierta, que es la condición misma de la puesta en práctica de la política, las autoridades, siempre susceptibles de recibir y dar golpes para resolver sus discordias, se ven obligadas a formar alianzas para mantener su rango y asegurar los intercambios de los que depende su economía. Por tanto, la competencia entre varias instancias de justicia, encarnadas por aquellas autoridades (capitán general, corregidores, alcaldes, oidores, propietarios de haciendas y estancias, padres de familia) capaces tanto de prestar asistencia como de aniquilar a cualquier habitante de la jurisdicción con el fin de corregirlo, merece atención a la luz de los análisis que ofrece la reciente historia social de la justicia en la América Hispana, y de un renovado enfoque de la historia política de los sentimientos (Albornoz Vásquez 2017).

En este contexto, en Santiago de Chile, como en otras partes del área hispano-católica, los otorgantes vienen ante el escribano para evitar 
posibles disputas ante la justicia ordinaria, que es demasiado cara, lenta y dura, como en la Península (Alonso Romero 2001: 30). Sentimientos como el temor a los retrasos judiciales, el miedo a una reputación mal manejada por su publicidad, la frustración de la justicia sin remedio, dan a los actos notariales una dimensión política. En este sentido, los otorgantes buscan al escribano para expresar los términos de un acuerdo, según una tradición antigua que lo considera una necesidad imperiosa para la supervivencia de la ciudad, ya que su ausencia la llevaría irremediablemente a la ruina (Akar 2013, González 2013). La escritura pública surge entonces como una necesidad práctica de contener el desorden político buscando el consenso. Con los parlamentos y los tratados con potencias extranjeras, los acuerdos ante escribanos pueden considerarse como tantas prácticas que llevan a los contemporáneos a favorecer, en ciertas ocasiones, el acuerdo en lugar de la confrontación, o a abandonar la segunda en favor de la primera. Se trata de una cultura política del consenso que empuja a los individuos a desarrollar un pensamiento autorreflexivo en términos de acuerdo, más que en términos de discordia.

La presencia, en los registros notariales, de instrumentos denominados convenios, compromisos, acuerdos y transacciones, entre otros, ponen de manifiesto el valor social de la acción extrajudicial en este contexto colonial. Así, en Santiago de Chile, la necesidad de producir armonía en lugar de conflicto y malos recuerdos se refleja no solo en el "parentesco espiritual" que proviene del compadrazgo (Zúñiga, 2002: 293-301), sino también en la abundante práctica del poder notarial, como salida generalizada a los desacuerdos latentes; en las fianzas, que permiten obligar legalmente a los individuos a ser dependientes de otros, sin caer en las prohibiciones de otras formas de servidumbre; en las obligaciones de pago y las compraventas, así como en todas las formas escritas que puedan adoptar las cláusulas resolutorias en testamentos, asientos, reconocimientos de deuda, convenios, acuerdos, transacciones, etcétera.

Estas prácticas lingüísticas cotidianas inducen vínculos sociales que expresan el apego al bien común y el amor a la patria. En 1673, en su célebre obra política en forma de relato de su Cautiverio, Francisco Núñez de Pineda y Bascuñán se refiere a la idea del hijo de la patria, en la que el concepto de patria incumbe a los individuos que son "eslabones de una jerarquía, sujetos a las órdenes de las autoridades que, a su vez, dependen de la Corona", de modo que, en palabras de la historiadora Lucía Invernizzi Santa Cruz, "un error en las decisiones que afectan al gobierno daría lugar a una multiplicación de los efectos nocivos" (Invernizzi Santa Cruz, 2002: 195). El vínculo social está garantizado por esta devoción al bien público. Así, junto con las causas penales, el interés heurístico de los documentos notariales, en particular de los acuerdos, transaccciones, compromisos, concertajes, contratos, advenimientos y asientos, cuyos números van aumentando en el siglo XVIII, muestran las prácticas cotidianas relacionadas con las necesidades económicas y políticas del consenso y las técnicas de subjetivación que inducen.

En este ámbito, el saber práctico del escribano tiene como objetivo acomodar las voluntades de las partes sin que siempre sea posible determinar quién es soberano en los intercambios privados: la voluntad de una de las partes para lograr sus fines, o la del poder del registro como garante de la paz social. El registro notarial aparece así como medio para aliviar las tensiones, debilitar a los rebeldes y ensordecer los escándalos. Se sabe, por ejemplo, que la prohibición de la usura ha llevado a utilizar las obligaciones legales para ocultar las operaciones de crédito (Muñoz 2001; Burns 1999; Wasserman 2018); que la práctica del indulto ante un notario público puede llevar a la extinción de los conflictos judiciales (Argouse 2014 ; Melo Flórez 2020). Los escribanos también son competentes en la recaudación de rentas, donde los numerosos préstamos de las arcas de las comunidades de indios se hacen inevitables, por lo que también pasan por fiscalizadores. En otras ocasiones, ocultan los acuerdos realizados ante ellos a los administradores del reino, argumentando que han jurado mantener las escrituras en secreto. Con ello adquieren un poder que la sociología de las organizaciones ha ayudado a describir, destacando sus conocimientos jurídicos, traducidos entre otras cosas por sus técnicas de archivo y su profesionalización para imponerse ante abogados, fiscales, corregidores y autoridades judiciales locales (Herzog 2004; Argouse 2017). De cierta manera, de la fuerza del derecho, del que los escribanos son expertos, se desprende la autoridad necesaria para generar consenso. Así, en San Felipe de los Andes, el fin de los Tribunales de Conciliación coincidió con el 
esfuerzo de clasificación de los archivos notariales de la ciudad por el notario Francisco Villegas en 1836 (Albornoz y Argouse 2017).

\section{Fisionomía de los registros: hacia una precisión en la designación de los instrumentos}

Sin pretender aquí entrar en el detalle del contenido de los textos acerca del consensualismo y sus formas jurídicas, y luego comprobar lo que sucede en la práctica notarial en Santiago de Chile, hemos optado, sobre la base de los registros de algunos de los escribanos de la ciudad, por examinar el lugar de las escrituras relativas a ciertos acuerdos entre partes en el conjunto de los instrumentos notariales.

Para ello, recurrimos en primer lugar a los índices de los protocolos, que son obligatorios. Pero en Santiago de Chile no se conservaron sistemáticamente, sin duda por su vulnerabilidad material: ubicados en las primeras páginas, sufren de la manipulación de los volúmenes. Afortunadamente, a falta de un índice, un importante número de volúmenes permite llevar la observación cuantitativa mediante un vistazo a las anotaciones en los márgenes. Además, gracias a los estudios emprendidos a partir de finales de los años 1960 por el profesor Sergio Martínez Baeza y sus estudiantes, pudimos completar nuestra exploración de los registros y constatar que ciertos tipos de acuerdos ante escribano van en aumento en el siglo XVIII.

Se desprende de nuestro corpus que, de manera general, en Chile, la actividad extrajudicial de los otorgantes se desarrolla principalmente en la esfera de la administración de bienes propios y la gestión de negocios a distancia, lo que se traduce en los registros por una sobresaliente mayoría de poderes, obligaciones y ventas. En Santiago de Chile, el poder es notablemente el instrumento más recurrente (alrededor del 20-25\%), seguido por las obligaciones. Tal como en otros lugares, las obligaciones reflejan una fuerte propensión a vivir a crédito y no necesariamente la seguridad del pago [Fontaine 2008, Muñoz 2001, Wasserman 2018]. Los poderes, con las fianzas, expresan también estas prácticas crediticias. Así, en un acuerdo hecho ante Gaspar Valdés, para hacer un retablo y un tabernáculo para la capilla de Nuestro Padre Jesús Nazareno que "esta principiado y a trabajar por Francisco Sid Maldonado" por un período de ocho meses por el precio de 1.600 pesos, el pago está afianzado por el capitán Miguel de Piñoa (ANHCh, Real Audiencia, vol. 95, folio 19) ${ }^{1}$.

Los registros de escribanos de Santiago de Chile informan también acerca de la circulación de las personas mediante las ventas y los testamentos: numerosas ventas de esclavos, especialmente por parte de mujeres que los poseían como propiedad propia, probablemente con dote, se suman a las cláusulas testamentarias mencionando a los esclavos y esclavas entre las propiedades transmitidas. Los registros aciertan la circulación de personas indias, poniéndose al servicio de amos españoles mediante los asientos para actividades de servicio doméstico. Otro reflejo de relaciones jerárquicas son las fianzas que llegan a casi el $7 \%$ de los actos notariales según nuestro sondeo para los siglos XVII y XVIII. Estas proporciones se mantienen a lo largo del periodo. Así, en general, los instrumentos que crean obligaciones (ventas, obligaciones y poderes) son los más repetidos.

Sin embargo, la cuestión de la clasificación de los instrumentos jurídicos ha sido planteada repetidamente por la historiografía de la práctica notarial. En cuanto a la forma en que el escribano nombra en el margen los instrumentos que redacta, hasta ahora se han identificado casi 253 variantes solo en el caso de Gaspar Valdés, escribano entre 1684 y 1715 . Se puede optar por agruparlas en categorías para facilitar la lectura, pero es una operación delicada. En efecto, ¿dónde clasificar un "consentimiento y carta de pago" ¿ ¿Una "carta de pago y finiquito"? ¿Un "poder y transacción”? cuando cada una de estas categorías también existe por sí sola. Hace falta hacer hincapié en las formas empleadas por cada escribano. Por ejemplo, en los volúmenes del notario Juan de Agurto Gastañaga, el término "chanzelación" puede referirse a un pacto que pone fin a un pleito. Es el caso de los hermanos Matías de Toro y Córdoba y Pedro de Salinas y Córdoba que, considerando que han gastado bastante dinero en el pleito que se les opone por la herencia de la casa de su madre y sobre todo "por la duda que ay en el fin de dicho pleyto", deciden transigir ante un escribano. La escritura se registra como "chanzelación", en el margen. Parece que se eligió el término para destacar una acción en lugar de la otra: la anulación de la deuda, derivada de una transacción, y no la transacción misma. Así, aunque cada instrumento siga un formulismo similar, tanto la redacción como los términos cambian de un 
documento al otro como de un escribano al otro. Por ejemplo, el pacto de no volver a hablar de los hechos de la causa puede ir acompañado, o no, de una multa. Por tanto, las partes pueden comprometerse a no modificar el pacto ante escribano bajo pena de una multa de 1.000 pesos [ANHCh, Escribanos de Santagio, vol. 403, folio 118, 1697].

Con el tiempo, observamos que los escribanos de Santiago tienden a ser más precisos en su uso de categorías jurídicas para calificar a los instrumentos extrajudiciales. Mientras más avanzamos en el siglo XVIII, más convenios, compromisos, transacciones, pactos, apartamientos, avenimientos y desistimientos aparecen en los registros notariales, es decir instrumentos basados en la búsqueda de consenso para evitar o solucionar un conflicto. No obstante, en este rápido panorama de las escrituras notariales en Santiago de Chile, los convenios, acuerdos, compromisos y transacciones siguen siendo minoritarios y los registros de la Real Audiencia y del capitán general deberían ser examinados a fondo para comparar los ritmos de judicialización o notarialización de los desacuerdos y conflictos.

También, la falta de abogados que representen los intereses en conflicto ante los tribunales puede explicar el recurso al compromiso o la transacción, con el nombramiento de un intermediario para negociar antes de que el conflicto desemboque en una acción judicial en la que un desequilibrio de poder pueda perjudicar a una de las partes. Por su lado, las pocas cartas de pago son un indicio de su débil capacidad de pagar desacuerdos derivados del crédito y de poner fin a posibles situaciones conflictivas. Es tan así que la causa de la obligación jurídica de pagar las deudas parece radicar en el establecimiento de un vínculo por escrito más que para asegurarse el pago. De esta manera, la mayoría de los instrumentos notariales proporcionan herramientas para protegerse de las incertidumbres del tiempo. Se trata en definitiva de un mundo de posibilidades - posibles arreglos futuros- que se abre mediante el oficio del escribano. Sobre todo, esta acción de escritura permite a los otorgantes o partes inscribirse en el registro auténtico de los titulares de derechos.

El concepto de tiempo permite asimismo distinguir en el registro notarial entre, por un lado, los instrumentos programáticos, tales como las obligaciones, los testamentos o los poderes, que refieren a una situación futura y, por otro lado, a los instrumentos que permiten resolver situaciones predeterminadas tales como las cartas de pago, compromisos y transacciones. En 1787, François-Benoît de Visme en sus anotaciones a la Ciencia perfecta de los notarios del abogado francés Claude-Joseph Ferrière (1682) calificó a estos últimos
"instrumentos que se hacen como conse- cuencia de los juicios, o para lograrlos, o para detenerlos, o para continuarlos; como todos los compromisos, transacciones, retiros, oposiciones, renuncias, actos de apelación, renuncias a las apelaciones y similares." (Ferrière, 1787: 422).

En la operación de categorización de los instrumentos redactados por los escribanos de Santiago, aislamos entonces a los instrumentos que refieren a ciertos contratos innominados entre partes: transacciones, ajustes, avenimientos, convenios, compromisos, desistimientos, apartamientos.

Un punto importante es notar que estos contratos tienen que ver con situaciones en las que los desacuerdos surgen en la ejecución de obligaciones derivadas de situaciones previas. Así, las particiones y divisiones de bienes necesitan la designación de componedores - a veces abogados de la Real Audiencia- para proceder a la liquidación de las sucesiones, ya que las partes no logran ponerse de acuerdo después del fallecimiento del De Cujus. También, varios convenios están vinculados a contratos (conciertos) para mejorar casas y a su controvertida ejecución. Es el caso de la reconstrucción de la casa del oidor Juan de la Cueva y Lugo por el carpintero José de Miranda en 1708 (ANHCh, Escribanos de Santiago, vol. 420, folio 150v, 1708). Cuando el oidor Juan de la Cueva llegó a Santiago a servir su plaza, no tenía casa y tuvo que "acomodarse en las casas de los herederos de don Juan Pasten" que estaban

\footnotetext{
"demolidas, ynauitables executadas y enbargadas por el tribunal de sensos de yndios por los ympuestos sobre ellas y fue nesess[ari]o repararlas de lo que paresio nesess[ari]o que era menester para poder las auitar" (ANHCh, Escribanos de Santiago, vol. 420, folio $150 \mathrm{v}, 1708$ )
}

Joseph de Miranda fue contratado para proceder a algunas obras de carpintería y a recibir por ello 200 pesos "en diferentes partidas". Pero "auiendo 
sobrebenido el caso de hauer salido el d[ic]ho s[eño] $r$ oydor de esta ziudad no se pudo por entonzes ajustar la q[uen]ta de lo q[ue] ymportaba las obras echas". Es decir, se trataba de determinar si las obras hechas implicaban ajuste de la cuenta a favor del carpintero o del oidor, el primero alegando que su valor superaba 1.000 pesos. Las partes deciden proceder a una transacción de tal manera que

"sobre los dozcientos pessos q[ue] tiene rezeuidos el d[ic]h Joseph de Miranda ahora reziue de presente trecientos pesos de a ocho r[eales] librados en la caxa Real de esta ziu[da]d de los salarios q[ue] en ella tiene debengados el d[ic]cho s[eño]r oydor para q[ue] se los paguen los ofic[iales] r[eales] de $\mathrm{d}$ [ic]ha $\mathrm{R}$ [eal] Caxa en virtud de esta escript[ur]a o de libram[ent]o (ANHCh, Escribanos de Santiago, vol. 420, folio $150 \mathrm{v}, 1708)$

Con los quinientos pesos recibidos, Joseph de Miranda se da por contento.

En general, los contratos de este tipo, así como otras garantías aportadas a la buena ejecución del trabajo, denotan precisión en la descripción de las obligaciones de las partes. Los desacuerdos surgen entonces de la dificultad por ejemplo para ajustar cuentas y estimar el valor del trabajo realizado, es decir, a posteriori, como entre Joseph de Miranda y el oidor De la Cueva. Es decir, que hacen referencia a elementos que ocurrieron durante la ejecución del contrato y que modifican las condiciones iniciales. Entre el capitán Bernardo de Herrera, dueño de un barco, y el capitán Antonio Buytron, la discordia surge así de lo complejo del ajustamiento de las cuentas:

Dijeron q[ue] por quanto han tenido diferencias sobre el ajustam[iento] de q[uen]tas de todas las dependencias q[ue] los susodichos an tenido y considerando q[ue] los pleitos son largos y costosos y el suseso de ellos yncierto an benido en comprometerse [...] (ANHCh, Escribanos de Santiago, Gaspar Valdés, vol 418, folio 86).

La justificación habitual que se da entonces para acudir al escribano es la ineficacia del procedimiento judicial para resolver el asunto y el dinero invertido o arriesgado en los costos procesales. $\mathrm{O}$ que la situación se ha vuelto demasiado compleja y se convoca que no se siga la causa judicial con crecidos gastos. Se precisa así el motivo de la transacción o del compromiso, es decir, determinar un precio razonado que pone fin a gastos interminables, ya que sucede a veces que las partes tienen que tomar préstamos para poder continuar su caso por vía judicial (ANHCh, Escribanos de Santiago, vol. 520, folio 43-57, 1724).

Parece que los costos de los pleitos alcanzan efectivamente tales cantidades irrazonables. Constituyen por lo tanto un límite financiero e imponen el recurso al pacto ante escribano. $\mathrm{La}$ irracionalidad entrevistada por las partes no corresponde a una abstracción: se mide por la probabilidad de una rápida resolución de la controversia ante el escribano, y por las posibilidades de ganancia o pérdida financiera así obtenidas en comparación con la situación inicial en juicio. En cierto modo, la causa judicial se agotó con los costos procesales, y el conflicto se desvanece con el tiempo, dando paso al imperativo de llegar a un consenso.

Al lado de este argumento en términos de intereses económicos, en los convenios y transacciones y otros contratos innominados se hace también referencia a la tranquilidad de los vecinos. Así, Manuel de Mena y José Antonio Alcalde, ambos vecinos de Santiago, expresan que su acuerdo es para "evitar pleitos posteriores entre vecinos" y han convenido "sobre el derecho cierto o dudoso a las tierras de la chacra de Cadupaja" (ANHCh, Escribanos de Santiago, vol. 793, folio 146, 1784).

Entonces, existen dos tipos de motivos, no excluyentes entre sí, para obligarse a respetar estos contratos: unos se desprenden de la voluntad de los otorgantes de rebajar los costos ; y otros, propios de estos contratos, se asemejan a una "retirada", literalmente a un "apartamiento" o "desistimiento" de la causa judicial, dos palabras usuales que dicen mucho acerca de la operación en cuestión: la abdicación del derecho a acudir a la justicia del rey para someter el acuerdo a otro arbitrio. En esta perspectiva, su aumento durante el siglo XVIII llama la atención.

\section{Abdicación de sí mismo ante el imperativo del consenso}

El vocabulario utilizado en los instrumentos es el de una terminación consensuada de los contratos anteriores (rotos y cancelados) y una promesa de 
no mover el dicho pleito. Las partes se desisten, apartan y renuncian a cualquier acción y derecho que les competa. El contrato tiene entonces la autoridad de res judicata que permite detener cualquier posible acción relativa a los hechos referidos en él. Se refuerza así con un juramento: "para mayor firmeza de este contrato juraron a dios y a la cruz que lo guardaran y cumpliran", también según una formulación recurrente. Por tanto, es a una obligación perpetua de no hacer que se comprometen las partes.

\begin{abstract}
"y que de este juramento no pedirán absolución ni relajación a que de derecho se la pueda conceder y si de propio motu le fuere concedido no usaran de ella [...] como si fuere por sentencia definitiva de juez competente consentida y no apelada y pasada en autoridad de cosa juzgada"(ANHCh, Escribano Gaspar Valdés, Vol. 420, folio 151-151v, 1708).
\end{abstract}

También en el compromiso hecho ante Joseph Álvarez de Hinostroza, escribano de Santiago, en 1715 aparece la referencia a la paz y unión y buena correspondencia entre las partes. Se trata de unas particiones de bienes donde aparecen dos hombres, el capitán don Mateo de Olivera y don Bartolomé de Martínez en representación de varias personas, y por consentimiento de doña Ysabel de Martínez, hermana de Bartolomé. El compromiso se hace

\begin{abstract}
"Por evitar las costas y dilaciones de los pleitos de particiones y conservar la paz union y buena correspondencia han tratado comprometer las d[ic]has particiones en persona de notoria virtud letras y desinteres que amigablemente los parta y divida para cuyo efecto se presentaron ante la Real Justicia pidiendo licencia [...]" (ANHCh, Escribanos de Santiago, Juan de Hinostroza, vol 507, folio 277, 1715).
\end{abstract}

La persona escogida es el abogado don Juan de Rosales, abogado de la Real Audiencia y lo que se le pide es de

"no formar autos ni estrepito de juisio [sic] [...] para que de ningun modo pasen a juicio contensioso a ningun tribunal por legitimo y competente que sea y guardando o no guardando la orden y forma del derecho [...]" (ANHCh, Escribanos de Santiago, Juan de Hinostroza, vol 507, folio 277v, 1715).

En el caso de que los componedores atribuyesen poco a una parte y mucha cantitad a la otra, las partes nombran hasta a un "juez en discordia" y:

“[...] aunque no se conforme con ninguno
de los jueces nombrados y no yran contra
ellos alegando lesión nulidad y engaño ni
valiendose del remedio de la apelación ni
de la reduzion a arbitro de buen baron por
que todo lo renuncian.” ANHCh, Escribanos
de Santiago, Juan de Hinostroza, vol 507,
folio $277 \mathrm{v}, 1715$

Así, la eficacia jurídica de este tipo de acuerdo entre partes parece corresponder no solo a un deber moral de respetar la palabra dada (Pacta sunt servanda), sino también a la renunciación a toda acción judicial. En efecto, a diferencia de una compraventa, cuya causa es la ejecución de las obligaciones de cada parte, estos contratos innominados (transacción, compromisos, acuerdos, etc.) implican una causa diferente. En la transacción mencionada arriba entre Manuel de Mena y José Antonio Alcalde, de 1784, se especifica que

"en esta virtud [de evitar los pleitos posteriores entre vecinos], Manuel de Mena se allana por vía de compensación o gratuita donación, a darle a José Antonio 200 cuadras de tierras [...] Don José Antonio cede a su vez al señor de Mena el resto de las tierras que en virtud de otros titulos podrían pertenecerles". (ANHCh, Escribanos de Santiago, Vol. 793, folio 146, 1784).

En el acuerdo precitado entre el oidor Juan de la Cueva y Lugo y el carpintero José de Miranda en 1708:

"ambos otorgantes cada uno por lo q[ue] les toca dijeron hauerse ajustado y combenido el $\mathrm{d}[\mathrm{ic}]$ ho pleito con equidad y justificación [...] y ambos otorg[aron] dieron por rotos y Chancelados los $\mathrm{d}[\mathrm{ic}]$ hos autos y prometieron q[ue] ahora ni 
en ningun tiempo no moberan el d[ic]ho pleito y del se desistieron y apartaron y renunciaron qualquiera accion y der[ech]o que les compita [....] (ANHCh, Escribanos de Santiago, vol. 420, folio 150v, 1708)

En cada caso, se trata por lo tanto de una abdicación de sí frente al imperativo del consenso. Los protagonistas "se allanan" y "ceden" y se dan por "contentos". Los motivos de estos contratos refieren entonces a la represión de la frustración y a la contención de las disputas interminables, al renunciar al derecho de continuar la acción judicial.

$\mathrm{Su}$ aumento en los archivos notariales durante el siglo XVIII corresponde al creciente número de decisiones judiciales que obliguen a las partes al silencio perpetuo y que "cortan la causa", trabajados por María Eugenia Albornoz Vásquez para Chile de los siglos XVII a XIX. En esta perspectiva, el estudio de estos contratos ante notarios permiten comprender que la disponibilidad de los jueces para satisfacer las demandas de las partes en conflicto que han acudido "a los tribunales" se fue reduciendo cada vez más a lo largo del siglo XVIII. El cuerpo del demandante exhibido en justicia, que ha llegado a sufrir ante el juez y obligarlo así a determinar la causa, tiende a dar paso a un corpus de instrumentos consensuales que registran las pretensiones de las partes, pero donde al juez judicial se substituye un árbitro designado por las partes o la voluntad de las partes. Este proceso histórico, observable a partir de los registros notariales, no significa que los motivos de los conflictos interpersonales no puedan resurgir ante los jueces judiciales. La extinción de la instancia judicial no significa que se extinga definitivamente el conflicto social.

\section{Conclusión}

La invención práctica del consenso en los archivos notariales de Santiago de Chile en los siglos XVII y XVIII se basó en a) la gestión de negocios a distancia, b) la falta de abogados para representar todas las partes, c) un mejor manejo de las categorías de instrumentos notariales por parte de los oficiales de pluma, d) la ineficacia de la justicia del juez y su carestía para la gestión de riesgos inherentes a todo tipo de contratos.

Interesarse en los motivos de la acción por escrito ante notario es cuestionar lo que lleva los otorgantes y partes a obligarse mutuamente, a partir de varios instrumentos notariales. Estos ponen de relieve un aumento de ciertos tipos de contratos que apuntan a la existencia de una exacerbación de la escritura notarial en general en la Capitanía General de Chile. Nuestra interpretación consiste en sugerir que este fenómeno obedece a la necesidad de producir sentido común, o consenso, en este contexto colonial conflictivo. Esta exacerbación es posible gracias a la oferta notarial, asegurada por la creación de nuevas escribanías en el siglo XVIII, a partir de 1713. Desde esta perspectiva, la escritura pública adquiere una función política que consiste en generar consenso y asegurar su reproducibilidad, abriendo un espacio en el que todos los habitantes de la ciudad pueden constituirse en sujetos hablantes y pensar en su existencia en común.

Las condiciones para el consenso ante escribano están vinculadas a la producción de un registro escrito de los acuerdos y controversias, cuya preservación está garantizada por la fe pública. Y aunque las tensiones que dan lugar a este registro escrito son la expresión de una relación de poder, en el mismo momento en que se registra esta inscripción, constituye una base sobre la que posteriormente se puede dispensar justicia y en la que participan hombres y mujeres de todos los estratos de la sociedad urbana colonial. Es vector de un sentido común, es decir, de un consenso.

\section{Agradecimientos}

Agradezco a Germán Morong y a Ana María Presta la posibilidad de publicar este texto en el Dossier que coordinan. También agradezco a lo/as evaluadore/a-s los aportes y correcciones.

\section{Referencias Citadas}

Agüero, A.

2008 Castigar y perdonar cuando conviene a la República. La justicia penal de Córdoba del Tucumán, siglos XVII y XVIII. Centro de Estudios Políticos y Constitucionales, Madrid.
Akar, $\mathrm{Ph}$.

2013 Concordia. Un ideal de la classe dirigeante romaine à la fin de la République. Presses Universitaires de la Sorbonne, París. 
Albornoz Vásquez, M. E.

2007 "El mandato de silencio perpetuo. Existencia, escritura y olvido de conflictos cotidianos, Chile, 1720-1840", in Cornejo C., Tomás y González Undurraga, C. (dir.). Justicia, poder y sociedad: recorridos históricos. Chile, siglos XVIII-XXI. Ed. Universidad Diego Portales, Santiago de Chile.

Albornoz Vásquez, M. E (dir.).

2016 Sentimientos y Justicia. Coordenadas emotivas en la factura de experiencias judiciales. Chile, 1650-1990. Acto Editores, Santiago de Chile.

Albornoz Vásquez, M. E. y Argouse, A.

2017 "Apuntando deseos, pasiones y poderes: registrar vínculos para 'levantar villa'. Los escribanos de San Felipe de Aconcagua, Chile, 1742-1842". Fronteras de la Historia 22, 2: 12-43.

Alonso Romero, M. P.

2001 "El solemne orden de los juicios : la lentitud como problema en la historia del proceso en Castilla". Anuario de la Facultad de Derecho de la Universidad Autónoma de Madrid 5: 23-54.

Argouse, A.

2017 "Prueba, información y papeles. Hacia una plena inclusión del escribano y de sus agencias en la historia de la justicia en Hispanoamérica (Chile, siglos XVII-XVIII)". Revista Historia y Justicia 8: 97-137.

Argouse, A.

2016 "Razón y secreto en los registros notariales virreinales. Madrid, Lima y Santiago de Chile (1670-1720)". Historia Crítica 60: 23-41.

Argouse, A.

2014 'Ausente como si fuésedes presente'. Perdón, injuria, escribanos y memoria en Chile, siglos XVI-XVIII", Revista Mouseiôn, Revista do Museu e Arquivo Historico La Salle 18, mayo/agosto: 55-74.

Argouse, A.

2013 "De los momentos del delito al monumento archivístico: el expediente criminal del oidor Leon. Santiago de Chile, 1673-1675". Revista Historia y Justicia 1, Dossier "Ficción, archivo y narrativas judiciales": 1-27.

Argouse, A. y Soliva Sánchez, M.

2019 “'Ningún documento es inocente'. Las marcas del papel en cinco volúmenes del fondo Escribanos de Santiago de Chile, ca. 1680-1720". Temas Americanistas 42: 9-3.

Asenjo González, M.

2013 “La concordia y el ‘bien común’ en los pactos y acuerdos de la vida política de las ciudades castellanas de la Baja Edad Media" en Nieto Soria, J. M. y Villarroel González, O. (ed.). Pacto y consenso en la cultura política peninsular. Siglos XI al XV. Ediciones Silex, Madrid: 387-410.

Bravo Lira, B.

1989 "La institución notarial en Chile. Notas sobre su origen y configuración jurídica" en Bravo Lira, B. Derecho común $y$ derecho propio en el nuevo mundo. Editorial Jurídica de Chile, Santiago: 265-275.
Burns, K.

1999 Colonial Habits. Convents and the Spiritual Economy of Cuzco, Peru. Duke University Press, Durham and London.

Dougnac Rodríguez, A.

1997 "El escribanato de Santiago de Chile a través de sus visitas en el siglo XVIII", Revista de Estudios HistóricoJurídicos XIX, Santiago de Chile: 49-93.

Ferrière, C.-J.

1787 La science parfaite des notaires. Nouvelle Edition revue corrigée et augmentée sur celle de feu Me. ClaudeJoseph de Ferrière par le Sieur F. B. De Visme. Tome 2. Jean Trebua, Paris.

Fontaine, L.

2008 L'économie morale. Pauvreté, crédit et confiance dans l'Europe préindustrielle. Gallimard, París.

Herzog, T.

2004 Upholding Justice. Society, State and the Penal System in Quito (1650-1750). The University of Michigan Press, Ann Arbor.

Invernizzi Santa Cruz, L.

2002 "El testamento como instrumento de regulación y control de la sociedad chilena del siglo XVII" en Julio Retamal Ávila (éd.), Estudios coloniales. Tomo II. Editorial Biblioteca Americana: Universidad Andrés Bello, Santiago du Chili: 193-205.

Melo Flórez, J. A.

2020 La cara oculta de la justicia. El perdón en la justicia y el gobierno de la monarquía hispánica en el virreinato del Nuevo Reino de Granada, 1739-1808. Tesis para obtener el título de Doctor en Historia. Colegio de Michoacán, Centro de Estudios Históricos, Zamora, Michoacán.

Muñoz, J. G.

2001 "Las obligaciones de Colchagua, Chile, en el siglo XVI" in Héctor Noejovich Ch. (ed.), América bajo los Austrias : economía, cultura y sociedad. Pontificia Universidad Católica del Perú, Lima: 321-333.

Núñez de Pineda y Bascuñán, F.

2001 [1673] Cautiverio Feliz. Edición crítica de Mario Ferreccio y Raïssa Kordi Riquelme. Estudio preliminar de Cedomil Goic. Ril Editores, Santiago de Chile.

Thayer Ojeda, T.

1914 Guía para facilitar la consulta del Archivo de Escribanos que se custodia en la Biblioteca Nacional. Imprenta Universitaria de Chile, Santiago de Chile.

Wasserman, M.

2018 Las obligaciones fundamentales : crédito y consolidación económica durante el surgimiento de Buenos Aires. Prometeo Libros, Buenos Aires.

Zúñiga, J. P.

2002 Espagnols d'Outre-Mer. Émigration, métissage, et reproduction sociale à Santiago de Chili, au 17e siècle. Édition de l'École des Hautes Études en Sciences Sociales, París.

\section{Notas}

1 El volumen 1195 de la Real Audiencia corresponde a un registro de escrituras del escribano Gaspar Valdés. 